January 6, 2010

\title{
Physical controls and interannual variability of the Labrador Sea spring phy- toplankton bloom in distinct regions
}

\author{
Eleanor Frajka-Williams ${ }^{a}$ (corresponding author) \\ e.williams@noc.soton.ac.uk \\ Peter B. Rhines ${ }^{a}$, \\ rhines@ocean.washington.edu \\ ${ }^{a}$ School of Oceanography, University of Washington \\ Box 357940 \\ Seattle, WA 98105, USA
}

\begin{abstract}
We investigated the variability of the spring phytoplankton bloom in the Labrador Sea, dividing into distinct biogeographical zones, then analyzing the relationship between the bloom and physical forcings. The spring phytoplankton bloom in the north Labrador Sea varied in intensity by a factor of 4 and in timing of onset by 3 weeks over the 11-year record from SeaWiFS satellite ocean chlorophyll, 1998-2008. This north bloom (north of $60^{\circ} \mathrm{N}$ and west of the Labrador shelves) is earliest and most intense, owing in part to the offshore-directed freshwater stratification from the West Greenland Current. On interannual timescales, significant correlations were found between the north bloom intensity and ocean processes, namely offshore advection, eddy activity and runoff from Greenland. In contrast, the central Labrador Sea is later and weaker, and only a correlation between the bloom timing and irradiance was found. As the subpolar gyre shifts in strength and shape, freshwater outflow from the Arctic and Greenland changes, we may expect further changes in the biological response as indicated by these relationships.
\end{abstract}

\section{Introduction}

Oceanic phytoplankton produce about half of the atmosphere's oxygen and form the basis for the oceanic food web. With SeaWiFS chlorophyll, it is possible to look at the dynamics and spatial structure of the spring bloom in remote areas such as the Labrador Sea at the western end of the subpolar North Atlantic (Fig. 1 1 ). The spring 
phytoplankton bloom in the subpolar North Atlantic dominates the annual cycle of chlorophyll. In the western subpolar gyre winter, deep mixing replenishes surface nutrients from Antarctic Intermediate Water, but light limitation restricts growth (Lévv, 2005). (This contrasts with the oligotrophic subtropical North Atlantic where nutrient levels in the subsurface reservoir are lower and the annual cycle of surface irradiance is reduced.) With the arrival of spring, mixed-layers shoal and irradiance increases. The bloom begins once photosynthetic production exceeds losses. Eventually, the bloom is arrested by competition for nutrients or pressure from grazer populations, peaks and declines.

Both the timing and magnitude of the bloom affect the transfer of energy to higher trophic levels (Townsend et al., 1994). The match/mismatch hypothesis between predator and prey cycles states that the survival of higher trophic levels with time-varying life stages depends on food availability at critical periods (Conover et al., 1995). Several physical effects are known to impact bloom timing or productivity, primarily light and stratification (Sverdrup, 1953). Their effect can be inferred from the description of the North Atlantic spring bloom above, that shallower mixed layers or more light result in an earlier bloom. In addition, overall production may be enhanced by higher light levels or nutrient availability, or the absence of grazers. Besides wintertime mixing, recent studies have shown the importance of mesoscale eddies to nutrient supply in the subtropical gyre (McGillicuddy et al., 1998; Siegel et al., 1999; McGillicuddy et al., 2007). However, the same eddy effects were shown to have an opposite effect in the Labrador Sea (McGillicuddy et al., 2003).

In the Labrador Sea, the importance of bloom timing and transfer of energy to higher trophic levels is especially important. Labrador Sea food chains tend to be short, enabling a description of the relationship between higher consumers such as cod, whale and bird populations to primary production (Conover et al., 1995; Laidre et al., 2007, 2008). Recruitment of copepods, the most abundant mezozooplankton in the region, depends on the supply of food (Head et al., 2000). Interestingly, while the general pattern of bloom timing in the North Atlantic tends to be earlier at lower latitudes and 
later at higher latitudes (Siegel et al., 2002), this pattern is reversed within the Labrador Sea (Head et al., 2000). An early explanation of the reversal was offered by Head et al. (2000), that ice melt from icebergs in the north Labrador Sea resulted in high stratification. A more recent study using a numerical model highlighted the importance of stratification for bloom timing patterns (Wu et al., 2008). Coincident in situ hydrographic and bio-optical measurements from a Seaglider during the 2005 spring bloom in the Labrador Sea also identified the importance of freshwater.

Bloom timing and differences in overall productivity between regions of the Labrador Sea indicate distinct biogeographical zones. These zones may also be associated with physical circulation patterns or watermasses which are partially responsible for setting mixed layer depths or nutrient levels. The general circulation within the Labrador Sea is cyclonic, characterized by doming isopycnals and layers of distinct watermasses in the boundary currents. The boundary currents and shelves are capped by very fresh, very cold water of Arctic origin. Extending from 200 to $800 \mathrm{~m}$ deep, encircling the Labrador Sea, is warm, saline Irminger Sea Water of subtropical origin. Labrador Sea Water formed during deep convection fills the central Labrador Sea from near the surface to $2500 \mathrm{~m}$ depth. Deeper lie Northeast Atlantic Deep Water and Denmark Strait Overflow Water which, together with Labrador Sea Water, make up North Atlantic Deep Water. Boundary currents are concentrated at the slopes by the Greenland and Labrador sides. Offshore advection around the northern edge of the Labrador basin occurs in two or more diffuse branches (Fig. 10). Deep waters are forced offshore by shoaling topography near the $3000 \mathrm{~m}$ isobath. This boundary current separation is visible as an eddy-kinetic-energy maximum (Fig. 10). Further outflow from the Greenland slope occurs near the $1000 \mathrm{~m}$ isobath. Within this offshore advection are found Irminger Rings, coherent mesoscale eddies which are characterized by the fresh shelf waters at the surface and Irminger Sea Water at intermediate depths.

Correspondingly, the Labrador Sea has been broadly divided into two biogeographical zones, associated with distinct watermasses and biological species (Longhurst, 2007; Devred et al., 2007). The primary zone is the Atlantic Arctic in the 
deep central Labrador Sea $(>2000 \mathrm{~m})$, characterized by high winter nitrate in the mixed layer $(\sim 15 \mu \mathrm{mol})$, an early bloom dominated by Phaeocystis ponchetti, followed by diatoms. The second zone is the Boreal Polar, corresponding to the cold, fresh Arctic waters on the shelves. For mezozooplankton, the shelves are dominated by Calanus hyperboreus (consistent with Boreal Polar) while the Greenland slope and north Labrador Sea have C. finmarchicus, and the central Labrador Sea, E. norvegica (consistent with Atlantic Arctic) Head et al. (2003). In the Irminger Sea, satellite and hydrographic-based studies showed that different zones have different bloom timing, due to population composition, mixing and stratification effects (Hollidav et al., 2006; Henson et al., 2006). In this paper, we explore biogeographical regions within the Labrador Sea using both SeaWiFS chlorophyll and distinctions in dominant physical controls between regions.

\section{Data \& Methods}

The domain for most of the study is the black box in Fig प $54^{\circ}$ to $66^{\circ} \mathrm{N}$ and $38^{\circ} \mathrm{W}$ to $65^{\circ} \mathrm{W}$.

\subsection{Satellite ocean color}

Ocean surface color measured by satellites is converted to an estimate of chlorophyll- $a$ concentration via an empirical algorithm (Feldman and McClain, 2006). The raw satellite signal is modulated by atmospheric effects, and affected by phytoplankton size and species, minerals and dissolved organic matter, resulting in an estimated error on chlorophyll of $\pm 35 \%$. We used OCV4 SeaWiFS daily, $9 \mathrm{~km}$ resolution mapped chlorophyll, photosynthetically active radiation (PAR) and attenuation coefficient at $490 \mathrm{~nm}\left(\mathrm{~K}_{490}\right)$ from 1998-2008 O'Reilly et al. (1998).At $60^{\circ} \mathrm{N}$, low incident sun angle in the winter results in no data prior to February and after October. For all analyses except the plots in Fig. [ data were binned to $0.5 \times 0.5^{\circ}$ resolution. Calculating annual cycles at a point, time series were first smoothed with a 3-day moving average. 
Maps of mean chlorophyll were calculated by averaging daily chlorophyll images from 1998-2008. (In this paper, "average" or "mean" refer to an arithmetic average.)

Bloom start day was calculated from SeaWiFS chlorophyll following Siegel et al. (2002) and Henson et al. (2006). For a given year $\left(\right.$ year $\left._{0}\right)$ and location, the start day (start) is defined as

$$
\operatorname{start}\left(\text { year }_{0}\right)=\min _{t \in \text { year }}\left\{\operatorname{chl}(t: t+3)>1.05 \times \operatorname{median}_{t \in \text { year }}\{\operatorname{chl}(t)\}\right\}
$$

where $c h l$ is chlorophyll concentration in $\mathrm{mg} \mathrm{m}^{-3}$ and $t \in$ year $_{0}$ indicates evaluating the expression over the time $t$ in days from year year 0 . In words, the start day is the first day when chlorophyll values exceed the annual median at that location by at least $5 \%$, and remain elevated for the 3 subsequent days or measurements. In some cases, e.g. when the shelf bloom was especially brief ( $<3$ days), our criterion for the bloom start day misidentifies the shelf bloom. For calculating the climatological start day for the 11-year record, we used median rather than mean. The resulting pattern (Fig. [2b) is somewhat earlier and smoother than if an arithmetic mean were used, primarily due to skewing towards a later start date at individual pixels that were cloudy around the start of the bloom. Within a geographic region, start day for that region is calculated as a spatial average of the start days at each pixel in the region.

To quantify interannual variability of the bloom we used empirical orthogonal functions $(\mathrm{EOF})$ on the de-seasoned, detrended satellite ocean color data. At each location, a linear trend was fit to the 11-year time series of chlorophyll and removed, then an annual cycle was calculated for the residual then subtracted from the time series. EOF analysis identifies spatial regions which covary in time, hopefully due to similar biological or physical forcings. The technique can be applied successfully to gappy data like SeaWiFS ocean color by using the covariance method of calculating EOFs rather than singular value decomposition (Kellv, 1988; von Storch and Zwiers, 2001, Chap. 13).

To focus on interannual variability, seasonal cycles and interannual trends were first removed at each location prior to the analysis. Varimax rotation was applied to improve the physical structure of the EOFs (Preisendorfer and Moblev, 1988). Homogenous 
correlation maps are calculated as a point-wise correlation between each principal component time series and the original time series at each location to ensure that the variability identified by the EOFs was intrinsic to the data (Preisendorfer and Moblev,

1988). High correlations indicate that the EOF is representative of that location. When we refer to EOFs in the text, it is the varimax-rotated pattern.

Cloudiness and ice cover in the region results in gaps in the SeaWiFS data set. The Labrador shelves are ice covered for much of the year, coastlines are occasionally obscured, and the central Labrador Sea is particularly cloudy. Over the time period considered, roughly $20 \%$ of the pixels have data, with roughly $10 \%$ coverage in March and nearing 35\% coverage in September. While coverage is patchy, perhaps due to small, fast-moving clouds, there may be data in one pixel and none in the adjacent several pixels. In this case, our methods of averaging (median for start day) and EOF analysis for gappy datasets can be expected to compensate somewhat for missing data. When large regions are missing for a week or more, as happens some years, the start day is skewed late and the bloom peak for the year may even be missing. While adding additional ocean color datasets may have lessened this issue, we chose to use only SeaWiFS in order to avoid complications of merging two products.

\subsection{Climatological and Argo hydrography}

Argo profiling floats collect a hydrographic profile from $2000 \mathrm{~m}$ to the surface every 10 days. Floats are ballasted to a depth between 750-2000 $\mathrm{m}$ and move with the currents. After a profile, they remain at the surface for $\approx 10$ hrs, transmitting data via the Argos satellite system. Float data were downloaded from http://www.nodc.noaa.gov/argo/accessData.htm for profiles since 2001, when salinity sensors were included. Floats on the Argo 'greylist', with problematic instruments, were discarded. With the World Ocean Atlas 2005 (WOA05) climatology product, we characterized the annual cycle of mixed layer depths and nutrients in the Labrador Sea. Mixed layer depths for both Argo floats and WOA05 were calculated 
using a density threshold. Density profiles were linearly interpolated to $20 \mathrm{~m}$ resolution in depth. The mixed layer depth was defined as the shallowest depth which had a density greater than the density in the surface $20 \mathrm{~m}$ bin by at least $0.1 \mathrm{~kg} \mathrm{~m}^{-3}$.

\subsection{Satellite altimetry}

Gridded geostrophic velocity products derived from satellite altimetry were produced by Ssalto/Duacs and distributed by Aviso with support from Centre National D'Études Spatiales (CNES). The delayed time reference product uses either TOPEX/Poseidon and Jason-1 or EnviSat and GeoSata altimeters, and objectively maps sea surface height anomalies to a $1 / 3^{\circ}$ resolution grid, weekly starting in 1992 . For absolute velocity, a background mean dynamic topography was added to the anomalies before calculating velocities. In both cases, velocities are calculated as surface geostrophic ocean currents ( $u$ zonal and $v$ meridional currents). We used the absolute velocity product when describing circulation in the Labrador Sea and velocity anomalies when calculating eddy-kinetic-energy (EKE),

$$
E K E=\frac{1}{2}\left(u^{2}+v^{2}\right)
$$

Offshore geostrophic velocities representing the offshore-directed branch of the subpolar gyre were estimated by averaging velocities perpendicular to the line in Fig. 8, with positive values to the southwest (in the direction of the gyre mean circulation). While the absolute velocities were used, and the position of the subpolar branch depends heavily on the background mean dynamic topography, for our calculations we are looking at interannual variability, which is not affected by the mean.

\subsection{Sverdrup's critical depth}

Sverdrup's critical depth theory predicts the timing of a spring bloom from physical properties (Sverdrup, 1953; Siegel et al., 2002; Henson et al., 2006). The theory balances 
depth-integrated production and respiration to estimate a critical depth for a bloom. Once the mixed layer depth is shallower than the critical depth, a bloom may begin. While the classic theory uses a simple parameterization of photosynthesis in terms of surface incident light (PAR) and exponential light attenuation $(k)$, and an assumed-constant respiration rate, it was found to be sufficient to describe the overall pattern in the Labrador Sea. Following Siegel et al. (2002) and Henson et al. (2006), the critical depth is defined as

$$
\frac{1}{k Z_{c r}}\left(1-e^{-k Z_{c r}}\right)=\frac{P A R_{c}}{P A R}
$$

One crucial parameter is not measured in situ: compensation irradiance $P A R_{c}$. It is the light necessary for photosynthesis to exactly balance respiration (Miller, 2004). While $P A R_{c}$ can vary with species, location and time, in absence of other measurements, we use $P A R_{c}=1.65$, a typical value for the region (Siegel et al., 2002). Since incident light (PAR) and mixed layer depth have annual cycles related to solar forcing and winter mixing, the bloom occurs when calculated critical depth intersects mixed layer depth. Once critical depth intersects mixed layer depth, the bloom in each region is predicted to begin.

\subsection{Convection Resistance}

A measure of stratification is the integrated buoyancy anomaly from the surface to a chosen reference depth $(h)$. While mixed layer depth gives one measure of stratification, it only describes how deep a very weakly stratified surface layer penetrates. Convection resistance represents the amount of buoyancy (in units of $\mathrm{kg} \mathrm{m}^{-2}$ ) which must be removed to convect to the reference depth, thereby capturing the intensity of the thermocline (if the chosen depth is below the thermocline). It can be further used to determine whether stratification is primarily haline or thermal. 
Convection resistance, or surface-to-depth buoyancy anomaly, is calculated as

$$
\operatorname{cr}(S, T, h) \equiv \int_{h}^{0} \sigma(S, T, z) d z-\sigma(S, T, h) h
$$

where $h$ is the reference depth, $\sigma$ the potential density, and $S$ and $T$ salinity and temperature (Bailev et al., 2005). Negative values are stable. To separate contributions from salinity and temperature, $\operatorname{cr}\left(S_{0}, T, h\right)$ and $\operatorname{cr}\left(S, T_{0}, h\right)$ are calculated, where $S_{0}$ and $T_{0}$ are fixed.

\subsection{Annual indices used to represent bloom variability and physical forcings}

From a time series of chlorophyll for a given region, an annual index to represent bloom timing was generated as the start day per year. Bloom magnitude was described by peak chlorophyll during the bloom as well as an integral of chlorophyll over the duration of the bloom. Duration was defined as the time from start day to end day, where the end day is the last contiguous day where chlorophyll was elevated above the threshold used for start day. For the integrated chlorophyll calculation, time series of chlorophyll were linearly interpolated over gaps. Peak and integrated-chlorophyll behaved similarly. Where they differ, the difference describes a change in shape of the bloom over time. When the peak is elevated relative to integrated-chlorophyll, it indicates a more intense, short-lived bloom with steeper increase or decline. When the peak is depressed relative to integrated-chlorophyll, it indicates a broader bloom in time.

Physical indices were chosen to represent irradiance, offshore advection of freshwater, eddy-activity and Greenland runoff. Light irradiance was represented by the annual average of SeaWiFS PAR in each region. Lacking interannual time series of stratification for the whole of 1998-2008, three proxies for freshwater were substituted:

(i) the offshore-directed branch of the subpolar gyre, (ii) eddies and (iii) runoff from Greenland (Fig. 10p and d). Mean offshore velocity was averaged from March through May directed perpendicular to the line given by diamonds in Fig. 8 While eddies travel at the mean background speeds, they are included as an additional proxy for freshwater 
since it is possible that they carry more freshwater than the background mean flow alone (Hátún et al., 2007). The eddy index was created by annually averaging

eddy-kinetic-energy from sea surface height anomalies within the north bloom region. Annual estimates of Greenland runoff were provided by Hanna et al. (2008) and Hanna, E (pers comm) from a meteorologically-forced numerical model.

\section{Climatology of the Bloom}

\subsection{Relative bloom magnitude \&6 phase}

Maps of mean chlorophyll identify two regions with highest concentrations: the north Labrador Sea (north of $60^{\circ} \mathrm{N}$ and east of $58^{\circ} \mathrm{W}$ ), and Hudson Strait outflow (Fig. 2a). The Hudson outflow signal is concentrated in the crescent shape at $60^{\circ} \mathrm{N}$ and $62^{\circ} \mathrm{W}$, and is reminiscent of river plumes in the northern hemisphere. The potential vorticity waveguide set by the shallow depth of the continental shelves directs the paths of shelf currents. In the case of buoyant river plumes, Coriolis causes them to turn right along the coast. However, the Hudson outflow first crosses to the shelf-break before turning right. The turning position may be determined by bottom Ekman stress balancing pressure gradients (Chapman and Lentz, 1994), though the theory does not account for the second observed front, between the coast and the outer front, which also reaches the shelf-break before turning with a different radius. High chlorophyll concentrations in the plume persist longer than in any other Labrador Sea bloom region, possibly due to a consistent nutrient supply from tidally-mixed Hudson Strait waters (Straneo and Saucier, 2008).

Differences in bloom phasing, here given by start day, indicate dynamically distinct regions. The overall pattern of bloom timing is that the north bloomed in the spring (April-May), central Labrador Sea later (June), and the Labrador shelves latest (June-July). The north bloom initiated nearly synoptically (within 2 weeks). The central Labrador Sea region, centered at $58^{\circ} \mathrm{N}$ and $55^{\circ} \mathrm{W}$, bloomed near the Labrador shelf then spread to the east and north. Annual cycles for the two bloom regions are 
shown in Fig. [3a, allowing direct comparison of bloom peak and start between regions. The north region has an early (late April) and very strong bloom, followed by a second peak in June-July. The last regions to bloom were the Hudson outflow and Labrador shelves (but see note regarding the bloom start day on the shelves in §refs:data Data and Methods). A Seaglider observed these same bloom regions in chronological order for the bloom in 2005, describing vertical profiles of fluorescence and coincident physical

properties (Frajka-Williams et al., 2009). The different phasing between these four regions (north, central, Labrador shelves and Hudson outflow) suggests different dynamics.

\subsection{Relating phase to physical properties}

Sverdrup's critical depth theory predicts the bloom start date using mixed layer depth and irradiance curves. Critical depths were calculated as described in $\$ 2.4$ and an annual cycle of mixed layer depths from Argo floats was calculated for the same two regions. Sverdrup's theory predicts that a bloom will start once the mixed layer depth and critical depth curves intersect (when $Z_{\text {crit }}$ is shallower than $M L D$. These curves predict the relative timing of the two blooms quite well (See Fig. Bb).

Based on Sverdrup's model, three hypotheses may explain observed bloom timing in Fig. 20:

- Variations in light are responsible for the pattern.

- Variations in stratification are responsible for the pattern.

- Or, untestable with available data, that variations in species composition, nutrient availability or pressure from grazers in the different biogeographical regions affect bloom timing, e.g. Phaeocystis ponchetti can take advantage of lower light levels than can diatoms, and so blooms earlier.

The first two hypotheses were tested using mixed layer depths from the WOA05 and an annual time series of PAR from SeaWiFS. Mixed layer depth cycles are linearly interpolated to match the higher horizontal and temporal resolution of the PAR 
product. Critical depth time series were calculated by solving (3) using SeaWiFS PAR time series and constant $\mathrm{PAR}_{c}$ and $k$. The predicted start day at each location is the first day when the mixed layer depth is shallower than the critical depth.

For the first hypothesis, a single basin-wide average cycle of mixed layer depths was calculated. By using a uniform annual cycle for the whole Labrador Sea, spatial variations in the predicted start day result directly from spatial variations in the annual cycle of light. In this way, we isolated the effect of light on the predicted start day (Fig. 4a). Over deep water, the predicted pattern of bloom initiation is latitudinal; lower latitudes bloom earlier because they receive more light. This latitudinal pattern contrasts with observed bloom start days: earlier in the north than the central Labrador Sea (Fig. 2). In both the predicted and observed pattern, Labrador shelves bloom late. Sea ice constrains the Labrador shelf bloom since incident light is small until ice melts.

For the second hypothesis, critical depths were averaged to create a spatially uniform cycle while annual cycles of mixed layer depth varied spatially. In this scenario, spatial variations in the predicted start day result from spatial variations in the annual cycles of mixed layer depth. Now, the predicted shelf bloom is coincident with the north bloom, much earlier than observed, while the phasing between the central and north Labrador blooms reflects the observed pattern: the north bloom is earlier than the central. Using a spatially uniform cycle of PAR implicitly neglects ice cover over the shelves which otherwise delays the shelf bloom. Shallow mixed layers in the north permit the earlier bloom, in line with observations.

Putting together both spatially variable light and mixed layer depth cycles, the predicted start day pattern was calculated (Fig. 4. 4 ). In this case, the relative timing of the north, central and Labrador shelf (early, later, latest) blooms matched observed phasing. One difference remained just seaward of the Labrador shelf. In the observed pattern, this bloom is later than the north bloom, but earlier than the Labrador shelf and central blooms. In the predicted pattern, the bloom is very early-at the same time as the north bloom. The skewed timing likely results from low horizontal resolution in the WOA05. Our method of linearly interpolating $1^{\circ} \times 1^{\circ}$ to higher resolutions spread 
the stratified shelf waters over the slope and deep water.

This test of Sverdrup's critical depth theory showed that stratification was responsible for the north Labrador Sea spring bloom timing, while light controlled the central Labrador Sea bloom. We used convection resistance to determine whether the stratification was due primarily to salinity or temperature. Climatological buoyancy anomaly to $500 \mathrm{~m}$ in May is shown in Fig. 5. The north bloom region (north of $60^{\circ} \mathrm{N}$ ) and the Labrador shelf are most stably stratified due to very stabilizing fresh water (Fig. [5) in spite of destabilizing cold temperatures (Fig. [5]). The central Labrador Sea, by contrast, is beginning to be thermally stratified in May and is also weakly haline stratified. This stratification information combined with Sverdrup's hypothesis demonstrates that, in the climatological average, the north bloom is early due to haline (fresh) stratification, the central Labrador Sea blooms later once thermal warming increases.

\section{Interannual Variability}

\subsection{Variability of chlorophyll}

A spatial time series of interannual variability in the north bloom (April-May) is shown in Fig. 6. Maps of mean chlorophyll during April-May of each year show the range in peak and pattern of the bloom. The largest blooms over the 2000-3000 m isobaths (around $62^{\circ} \mathrm{N}$ and $54^{\circ} \mathrm{W}$ ) are the 1998, 2002 and 2008 years. The 2002 bloom in particular was large and very concentrated. Other years, like 2003, were more confined to the Greenland shelf/slope area. Unfortunately, cloudiness during the peak bloom may obscure the extent and magnitude of the bloom.

EOFs were used to quantify interannual variability and to delineate the major regions of variability. The first two EOFs explain $49 \%$ and $10 \%$ of the data (Fig. (7). The shape of these patterns does not directly reflect climatology, since annual cycles were removed before calculating EOFs, but instead reflects the locations of high variability. The first EOF is representative of the north region with maximal variability at $63^{\circ} \mathrm{N}$ and 
$54^{\circ} \mathrm{W}$. Positive correlation also extends southward and slightly eastward to $56^{\circ} \mathrm{N}$. The second EOF is representative of the central Labrador Sea, concentrated between the 2000- and 3000-m isobaths between $55^{\circ}$ and $58^{\circ} \mathrm{N}$. The southeastward-extending branch of the first EOF is suggests the influence of mesoscale eddies as the map of peak EKE in the Labrador Sea has a similar structure (Fig. 10), while the second EOF includes the location of deep convection in the Labrador Sea (Pickart et al., 2002). Guided by these EOF maps and physical conditions associated with the bloom climatology ( $(3.2)$, we next relate the interannual variability to physical forcing.

\subsection{Relating interannual variability in bloom characteristics to physical forcing}

What physical conditions and processes affect the interannual variability of the bloom? Physical effects that impact timing include light and stratification. In particular, haline stratification is responsible for the climatological north bloom timing. Eddies may influence nutrient availability, either positively or negatively. The offshore advection of freshwater by the subpolar gyre consists of the mean and eddy flow. Sources of upper ocean stratification include local sea ice dynamics, melting from Greenland and changes in the Arctic freshwater outflow. Global warming is increasing the supply of surface freshwater in the region through increased ice melt of the Greenland ice sheet (Luthcke et al., 2006; Stearns and Hamilton, 2007; Hanna et al., 2008). Using indices to describe the state of these physical factors and bloom responses, we identified potential relationships between the bloom and physics.

We focus on the two regions of high variability-the north and central Labrador Sea-based on the EOFs in Fig. [7 and our understanding of distinct zones within the Labrador Sea from climatological bloom timing and magnitude (Fig. 8). For the north bloom, we used the region within $59-62^{\circ} \mathrm{N}$ and $52-54^{\circ} \mathrm{W}$, corresponding to high variance in the EOF, the location of the offshore branch of the subpolar gyre (at the $3000 \mathrm{~m}$ isobath) and peak eddy-kinetic-energy. For the central Labrador Sea, the region is within $56.25-57.75^{\circ} \mathrm{N}$ and $54.5-57.5^{\circ} \mathrm{W}$, corresponding to high variance in the second 
EOF and the location of deep convection.

Time series of SeaWiFS chlorophyll averaged within each box are shown in Fig. 9. The largest bloom years in the north $(1998,2008)$ do not correspond to the largest bloom years in the central region $(2004,2007)$. The bloom in the north is also larger, on average, than in the central region, which was clear in the annual cycles in Fig. 3 , though the regions used are slightly different. Start day was fairly consistent between years in the north region, ranging from April $11 \pm 8$ days in 1999 to May $5 \pm 7$ days in 2008, a range of over 3 weeks (start day for each region and year \pm standard deviation of start days in that region). The start day in the central Labrador Sea, on the other hand, ranged from April 27士19 days in 1999 (during which year there was hardly a bloom to speak of) to June $3 \pm 2$ days in 2007, a range of 6 weeks. In 2008, the entire Labrador Sea (north and central) bloomed together and early (Fig. 6), which will be briefly discussed further in the Discussion section.

Annual indices for bloom magnitude and timing were calculated for the two regions. Bloom magnitude indices for the north bloom region are shown in Fig. [10]. Annual physical indices were created to quantify light in both regions, and also for the north region, indices for the offshore advection of freshwater, eddy-activity and Greenland runoff. Index calculations are described in \$2.6.

The north bloom measures show the relationships between bloom start, duration, peak and integrated chlorophyll (Fig. 10a and c). Big bloom years occurred in 1998, 2002, 2003 and 2008, with noticeable dips in 2000 and 2004-2005. Highest runoff occurred in 1998, 2002-3, and 2006-7 (an estimate for 2008 was not yet available). In years when the peak chlorophyll is relatively higher than integrated chlorophyll (2002-2007), the duration is typically short ( $<25$ days). Generally, when a bloom begins earlier, it is also longer, except for the 2008 bloom which was late, long, and large. That the 2008 bloom persisted later into the summer may explain why it had higher peak magnitude and integrated chlorophyll, because more light is available later. Of all the variables, start day is the only one that appears to have a trend, with the earliest starts near the beginning of the record, and latest in 2008. During the 2008 spring bloom, 
both the north and central Labrador Sea regions bloomed within a few days of each other. Of the physical measures, runoff and eddy-kinetic-energy track fairly well, at least during the increase from 2000-2003. The pattern in offshore velocity resembles that of the subpolar gyre index (Hakkinen and Rhines, 2004; Hakkinen et al., 2008) though the latest years were not included in that paper. Both the gyre index and offshore velocity had minima in 2004 .

Correlations were calculated between bloom and physical indices for the 11-year record (10 in the case of Greenland runoff, for which 2008 was not yet available). Some of the time series are strikingly correlated (Fig. III). Eddy-kinetic-energy and Greenland runoff were both correlated with peak bloom in the north Labrador Sea for EKE and runoff, explaining $38 \%$ and $83 \%$ of the original variability, respectively. The table of $r^{2}$ values for all correlations is shown in Table 1 Assuming normal statistics and zero true correlation, $95 \%$ of sample correlation estimates based on 11 independent points will have $r^{2}$ values less than 0.36 . For the central Labrador Sea, the only significant correlation was between light and start day. For the north bloom, peak bloom correlated with offshore velocity, eddy activity, light and runoff; integrated chlorophyll with all but eddy activity. Start day was only correlated with offshore velocity. Estimating the peak bloom from physical parameters, we can write for the north bloom

$$
\begin{aligned}
& \text { peak intensity }=0.15 \times E K E-4.74, \\
& \text { peak intensity }=0.36 \times \text { Runoff }-7.65 .
\end{aligned}
$$

While it is possible to calculate multiple linear regressions, and in these cases explaining up to $85 \%$ of the variance in peak north bloom and $70 \%$ of integrated chlorophyll, it is not considered robust to use multiple independent (physical) variables for such a short (11-realization) record. 


\section{Discussion}

In this paper, we described the climatology of the bloom in the Labrador Sea, identifying major biogeographical zones and physical causes for variability in timing and magnitude. These physical effects highlight the sensitivity of the Labrador Sea ecosystems to climate change.

The north Labrador Sea (north of $60^{\circ} \mathrm{N}$ and east of the Labrador shelf) blooms early and intensely, while the central Labrador Sea blooms later, after deep convection has ended. Climatological variations in timing in the north bloom were due to stratification, while in the central Labrador Sea, were controlled by the annual cycle of light. Maps of buoyancy anomaly indicate that haline stratification is responsible for the early north bloom and explains the reversal of the overall northward progression of bloom onset, first identified by Head et al. (2000).

The relationship between physics and the bloom were described by indices for each effect (physical and bloom measure), the two regions (north and central) and each year. Correlations between physical and bloom indices suggest that light is responsible for variance in the central bloom timing, whereas in the north bloom light affects bloom intensity. Instead, duration in the north is related to the intensity of offshore velocities from the $3000 \mathrm{~m}$ isobath, one measure of the strength of the subpolar gyre. Overall gyre strength can also be represented by the gyre index (Hakkinen et al., 2008). The gyre has been slowing and changing shape from 1992-2006, which implies a reduction in offshore velocities. From our correlations, slowing of the gyre correlates with a shorter bloom and weakened bloom intensity.

Eddy-kinetic-energy was also shown to correlate with bloom intensity in the north bloom. Recent studies in mesoscale variability of biological activity suggest that eddies may vertically advect nutrients from deeper, richer waters (Klein and Lapevre, 2009). While previous model studies showed that eddies actually decrease nutrient availability in the Labrador Sea (McGillicuddy et al., 2003), which should adversely affect a bloom, our results are contrary. A third explanation for our results and those of

McGillicuddv et al. (2003) could be that eddies in this region do not supply additional 
nutrients, but rather aid in the haline stratification of the region, since these eddies tend to be fresh at the surface (Frajka-Williams et al., 2009).

Perhaps the most striking correlation was that between Greenland runoff and bloom intensity. Recent changes in ice dynamics of Greenland herald unexpected changes to ice melt and runoff which may affect local ecosystems (Luthcke et al., 2006; Stearns and Hamilton, 2007; Holland et al., 2008). Though Greenland ice melt is several physical steps removed from the bloom location, increased ice melt may steepen boundary gradients in the West and East Greenland currents, which could locally accelerate the subpolar gyre and/or increase the frequency of eddy-generation. Either of these physical effects could more directly affect the bloom intensity or, as we have seen, duration. However if there were a direct link between runoff and offshore velocity or eddy-kinetic-energy, one would also expect positive correlations between these physical indices, which while positive, were not significant.

The reduction of the gyre index through 2006 reversed in 2008, which was also the biggest bloom year in the north Labrador Sea. Also in 2008, the depth of deep convection in the Labrador Sea passed $2000 \mathrm{~m}$ for the first time in a decade (Väge et al., 2009). While freshwater is typically thought to condition the region against convection (as in the Great Salinity anomaly (Houghton and Visbeck, 2002)), paradoxically in 2008 this freshwater may have protected cold atmospheric winds until they reached the site of deep convection. The same increase in freshwater could be responsible for the changes in the 2008 bloom. It was larger, spatially as well as in magnitude and the central and north bloom were nearly simultaneous, but later, which is contrary to the suggestion by Sverdrup's hypothesis that increased stratification results in an earlier bloom. (A cursory look at Argo float data in our region showed that, while springtime salinities were lower than over the base period (2002-2008), mixed layer depths were not appreciably shallower.)

This paper demonstrates the strength of remote observations to diagnose variability in chlorophyll cycles. While linear regressions are suggestive of potential causation, they only show correlation. Processes and physical controls suggested by our analysis 
highlight the need for more in situ observations in the Labrador Sea, to describe the hydrography, nutrients and primary productivity, and directly identify dynamical links between physics and biology, here only suggested by simple correlations.

\section{Acknowledgements}

This work was performed with support from NSF Physical Oceanography grant. Eleanor Frajka-Williams was supported by an NSF graduate research fellowship for a part of this work. The manuscript was improved due to comments from anonymous reviewers. Many thanks to Eric D’Asaro, Bruce Frost, Erica Head, Hjalmar Hatun, Brandon Sackmann for interesting and helpful discussions. Many thanks to the people who gathered or provided data used here including the SeaWiFS data teams, AVISO, World Ocean Atlas and Argo projects.

\section{References}

Bailey, D. A., Rhines, P. B., and Hakkinen, S. (2005). Formation and pathways of North Atlantic Deep Water in a coupled ice-ocean model of the Arctic-North Atlantic Oceans. Journal of Climate, 25:497-516.

Chapman, D. C. and Lentz, S. J. (1994). Trapping of a coastal density front by the bottom boundary layer. Journal of Physical Oceanography, 24:1464-1479.

Conover, R. J., Wilson, S., Harding, G. C. H., and Vass, W. P. (1995). Climate, copepods and cod: some thoughts on the long-range prospects for a sustainable northern cod fishery. Climate Research, 5:69-82.

Devred, E., Sathyendranath, S., and Platt, T. (2007). Delineation of ecological provinces using ocean colour radiometry. Marine Ecology Progress Series, 346:1-13.

Feldman, G. C. and McClain, C. R. (2006). Ocean color web: SeaWIFs. In Kuring, N. and Bailey, S. W., editors, NASA Goddard Space Flight Center.

Frajka-Williams, E., Rhines, P., and Eriksen, C. (2009). Mesoscale variability in the Labrador Sea spring phytoplankton bloom observed by Seaglider. Deep Sea Research I, 56:2144-2161.

Hakkinen, S., Hatun, H., and Rhines, P. B. (2008). Satellite evidence of change in the northern gyre. In Dickson, R. R., Meincke, J., and Rhines, P., editors, Arctic-Subarctic Ocean Fluxes: Defining the Role of the Northern Seas in Climate, pages 613-628, Dordrecht. Springer. 
Hakkinen, S. and Rhines, P. B. (2004). Decline of subpolar North Atlantic circulation during the 1990s. Science, 304:555-559.

Hanna, E., Huybrechts, P., Steffen, K., Cappelen, J., Huff, R., Shuman, C., Irvine-Fynn, T., Wise, S., and Griffiths, M. (2008). Increased runoff from melt from the Greenland ice sheet: A response to global warming. Journal of Climate, pages 331-341.

Hátún, H., Eriksen, C. C., and Rhines, P. B. (2007). Buoyant eddies entering the Labrador Sea observed with gliders and altimetry. Journal of Physical Oceanography, $37: 2838-2854$.

Head, E. J. H., Harris, L. R., and Campbell, R. W. (2000). Investigations on the ecology of Calanus spp. in the Labrador Sea. I: Relationship between the phytoplankton bloom and reproduction and development of Calanus finmarchicus in spring. Marine Ecology Progress Series, 193:53-73.

Head, E. J. H., Harris, L. R., and Yashayaev, I. (2003). Distributions of Calanus spp. and other mesozooplankton in the Labrador Sea in relation to hydrography in spring and summer (1995-2000). Progress in Oceanography, 59:1-30.

Henson, S. A., Robinson, I., Allen, J. T., and Waniek, J. J. (2006). Effect of meteorological conditions on interannual variability in timing and magnitude of the spring bloom in the Irminger Basin, North Atlantic. Deep Sea Research I, $53: 1601-1615$.

Holland, D. M., Thomas, R. H., de Young, B., Ribergaard, M. H., and Lyberth, B. (2008). Acceleration of Jakobshavn Isbræ triggered by warm subsurface ocean waters. Nature Geoscience, 1:659-664.

Holliday, N. P., Waniek, J. J., Davidson, R., Wilson, D., Brown, L., Sanders, R., Pollard, R. T., and Allen, J. T. (2006). Large-scale physical controls on phytoplankton growth in the Irminger Sea part I: Hydrographic zones, mixing and stratification. Journal of Marine Systems, 59:201-218.

Houghton, R. W. and Visbeck, M. H. (2002). Quasi-decadal salinity fluctuations in the Labrador Sea. Journal of Physical Oceanography, 32:687-701.

Kelly, K. A. (1988). Comment on "Empirical Orthogonal Function analysis of advanced very high resolution radiometer surface temperature patterns in Santa Barbara Channel" by G. S. E. Lagerloef and R. L. Bernstein. Journal of Geophysical Research, 93(C12):15,753-15,754.

Klein, P. and Lapeyre, G. (2009). The oceanic vertical pump induced by mesoscale and submesoscale turbulence. Annual Reviews of Marine Science, 1:351-375.

Laidre, K. L., Heide-Jorgensen, M. P., and Nielsen, T. G. (2007). Role of the bowhead whale as a predator in west Greenland. Marine Ecology Progress Series, 346:285-297.

Laidre, K. L., Heide-Jorgensen, M. P., Nyeland, J., Mosbech, A., and Boertmann, D. (2008). Latitudinal gradients in sea ice and primary production determine Arctic seabird colony size in Greenland. "Proceedings of the Royal Society B", 275:2695-2702.

Lévy, M. (2005). Nutrients in remote mode. Nature, 437:628-631. 
Longhurst, A. R. (2007). Ecological Geography of the Sea. Academic Press, Amsterdam, 2nd edition.

Luthcke, S. B., Zwally, H. J., Abdalati, W., Rowlands, D. D., Ray, R. D., Nerem, R. S., Lemoine, F. G., McCarthy, J. J., and Chinn, D. S. (2006). Recent Greenland ice mass loss by drainage system from satellite gravity observations. Science, pages 1286-1289.

McGillicuddy, D. J., Anderson, L. A., Doney, S. C., and Maltrud, M. E. (2003). Eddy-driven sources and sinks of nutrients in the upper ocean: results from a 0.1 degree resolution model of the North Atlantic. Global Biogeochemical Cycles, 12.

McGillicuddy, Jr., D. J., Anderson, L. A., Bates, N. R., Bibby, T., Buesseler, K. O., Carlson, C. A., Davis, C. S., Ewart, C., Falkowski, P. G., Goldthwait, S. A., Hansell, D. A., Jenkins, W. J., Johnson, R., Kosnyrev, V. K., Ledwell, J. R., Li, Q. P., Siegel, D. A., and Steinberg, D. K. (2007). Eddy/wind interactions stimulate extraordinary mid-ocean plankton blooms. Nature, 316:1021-1026.

McGillicuddy, Jr., D. J., Robinson, A. R., Siegel, D. A., Jannasch, H. W., Johnson, R., Dickey, T. D., McNeil, J., Michaels, A. F., and Knap, A. H. (1998). Influence of mesoscale eddies on new production in the Sargasso Sea. Letters to Nature, 394:263-266.

Miller, C. B. (2004). Biological Oceanography. Blackwell Publising, Malden, MA.

O’Reilly, J. E., Maritorena, S., Mitchell, B. G., Siegel, D. A., Carder, K. L., Garver, S. A., Kahru, M., and McClain, M. (1998). Ocean color chlorophyll algorithms for SeaWiFS. Journal of Geophysical Research -Oceans, 103:24937-24953.

Pickart, R. S., Torres, D. J., and Clarke, R. A. (2002). Hydrography of the Labrador Sea during active convection. Journal of Physical Oceanography, 32:428-457.

Preisendorfer, R. W. and Mobley, C. D. (1988). Principal component analysis in meteorology and oceanography. Elsevier, New York, NY, USA.

Siegel, D. A., Doney, S. C., and Yoder, J. A. (2002). The North Atlantic spring phytoplankton bloom and Sverdrup's critical depth hypothesis. Science, 296:730-733.

Siegel, D. A., McGillicuddy, Jr., D. J., and Fields, E. A. (1999). Mesoscale eddies, satellite altimetry and new production in the Sargasso Sea. Journal of Geophysical Research, 104(C6):13,359-13,379.

Stearns, L. A. and Hamilton, G. S. (2007). Rapid volume loss from two East Greenland outlet glaciers quantified using repeat stereo satellite imagery. Geophysical Research Letters, 34 .

Straneo, F. and Saucier, F. (2008). The outflow from Hudson Strait and its contribution to the Labrador Current. Deep Sea Research I, 55:926-946.

Sverdrup, H. U. (1953). On conditions for the vernal blooming of phytoplankton. J. Cons. Int. Explor., 18:287-295.

Townsend, D. W., Cammen, L. M., Holligan, P. M., Campbell, D. E., and Pettigrew, N. R. (1994). Causes and consequences of variability in the timing of spring phytoplankton blooms. Deep Sea Research I, 41:747-765. 
Väge, K., Pickart, R. S., Thierry, V., Reverdin, G., Lee, C. M., Petrie, B., Agnew, T. A., Wong, A., and Ribergaard, M. H. (2009). Surprising return of deep convection to the subpolar North Atlantic Ocean in winter 2007-2008. Nature Geoscience, 2:67-72.

von Storch, H. and Zwiers, F. W. (2001). Statistical analysis in climate research. Cambridge University Press, Cambridge, UK.

Wu, Y., Platt, T., Tang, C. C. L., and Sathyendranath, S. (2008). Regional differences in the timing of the spring bloom in the Labrador Sea. Marine Ecology Progress Series, 355:9-20. 


\section{Figures}

a)

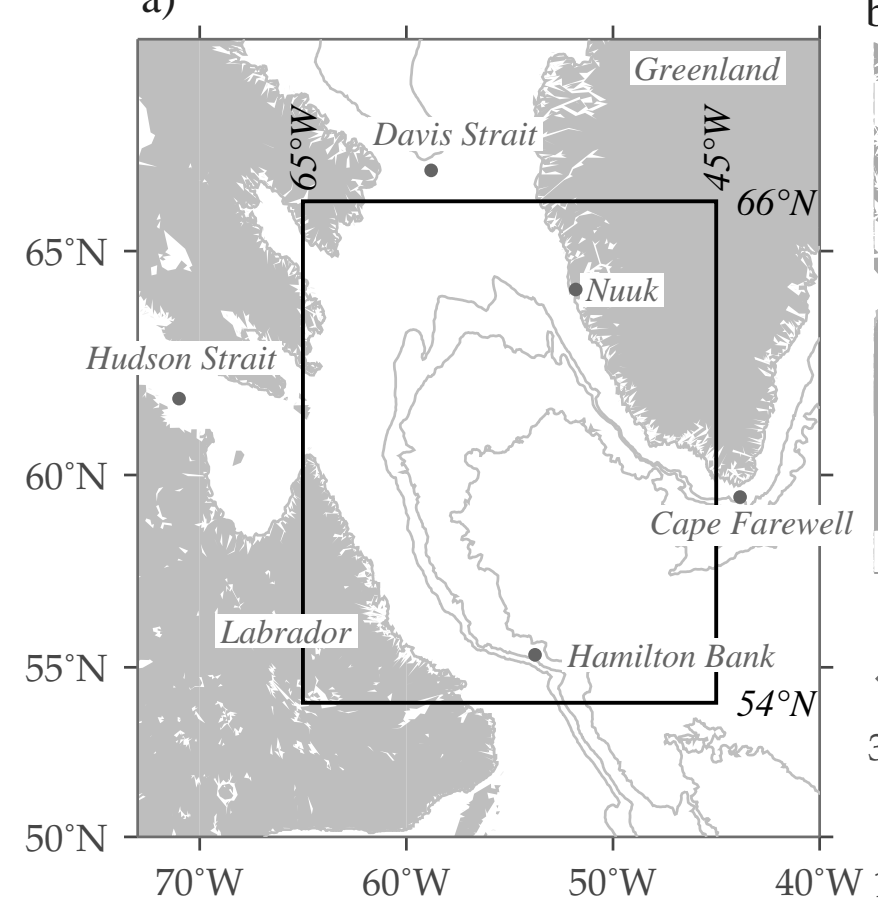

b)

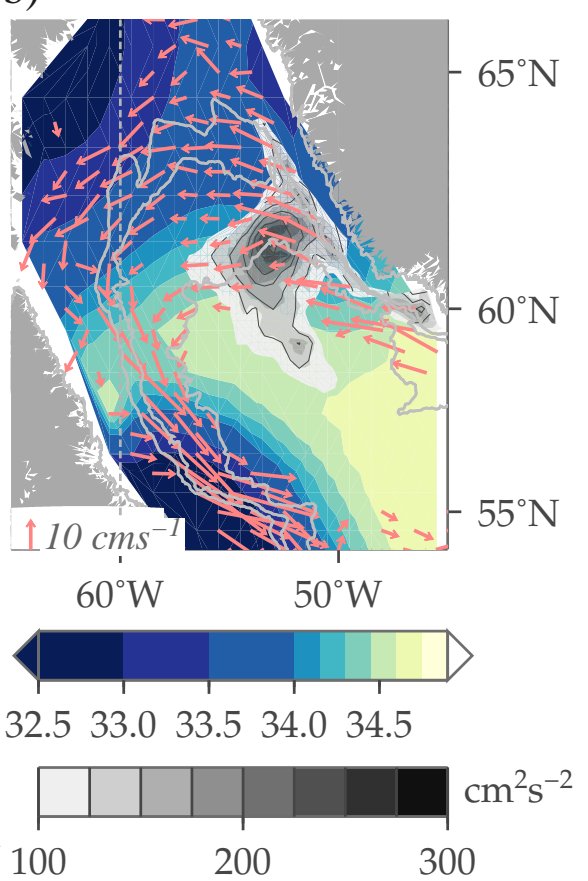

Figure 1: (a) Bathymetry in the greater Labrador Sea area. The black box marks the domain for this study.(b) General circulation patterns, climatological sea surface salinity and mean eddy-kinetic-energy. Circulation is cyclonic, following isobaths; freshwater is concentrated on the shelves and spread over the north Labrador Sea. Average eddykinetic-energy peaks at $62 \circ \mathrm{N}$ and $53 \circ \mathrm{W}$, where the $3000 \mathrm{~m}$ isobath turns away from the Greenland shelf.

a) Mean chlorophyll

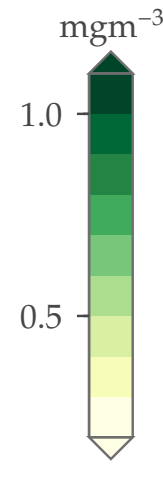

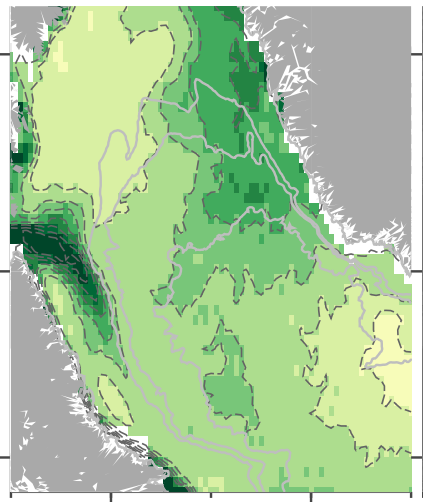

$60^{\circ} \mathrm{W}$ b) Bloom startday

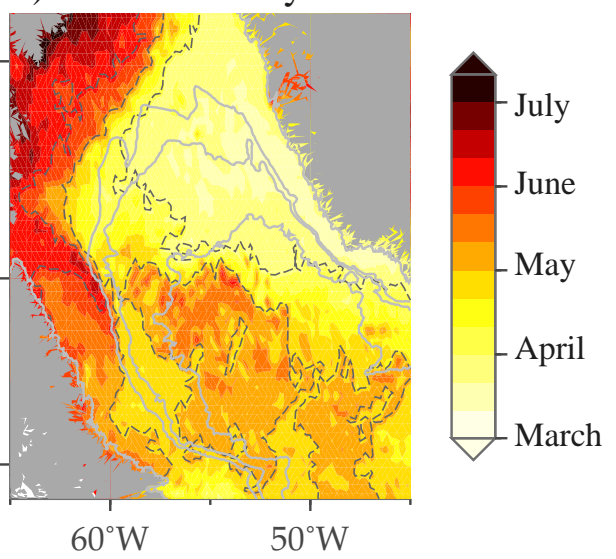

Figure 2: (a) Mean chlorophyll and (b) median start day of the bloom, from 1998-2008. High mean chlorophyll regions (a) include the plume exiting the Hudson strait at $60^{\circ} \mathrm{N}$ and $65^{\circ} \mathrm{W}$, and the dual-lobed feature off the coast of west Greenland, at $63^{\circ} \mathrm{N}$ and $57^{\circ} \mathrm{W}$ and $61^{\circ} \mathrm{N}$ and $55^{\circ} \mathrm{W}$. Note that the Labrador Sea north of $60^{\circ} \mathrm{N}$ blooms early, the Labrador shelves and Hudson outflow bloom late, while the central Labrador Sea is intermediate in both magnitude and timing. 
a) Chlorophyll annual cycle
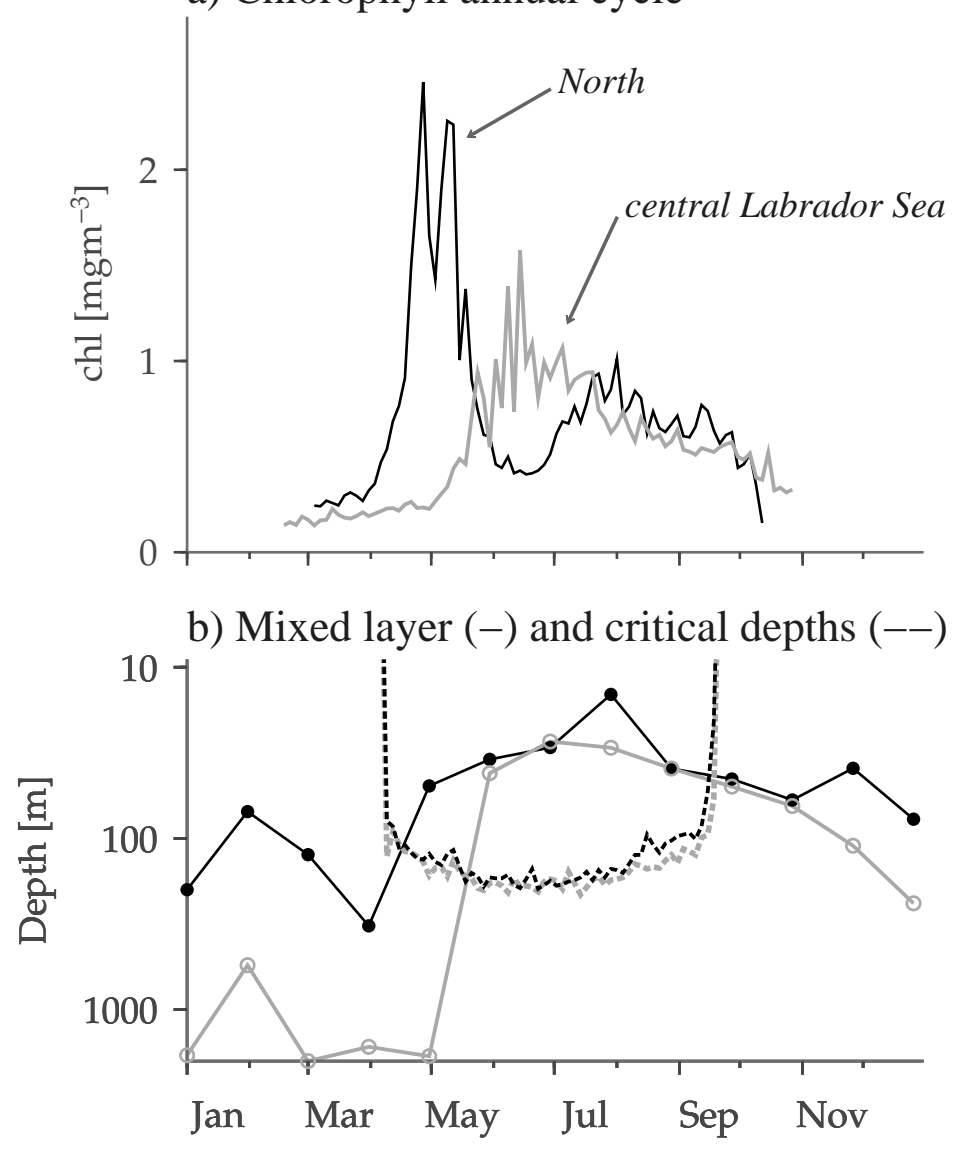

Figure 3: (a) Annual cycle in chlorophyll- $a$ concentration from SeaWiFS at two locations averaged over $1998-2008$. The northern location $\left(53.5^{\circ} \mathrm{W}\right.$ and $62^{\circ} \mathrm{N}$, black lines in both panels) has the strongest and earliest bloom. The central Labrador Sea blooms later and weaker $\left(55^{\circ} \mathrm{W}\right.$ and $58^{\circ} \mathrm{N}$, gray lines in both panels). (b) Annual cycle of mixed layer depth (solid lines with circles) were calculated from Argo floats profiling within $1^{\circ}$ of the target locations, and Sverdrup's critical depth (dashed lines) was calculated from SeaWiFS PAR. The mixed layer depth is first shallower than the critical depth around April for the north and mid-May for the central Labrador Sea. 
a) variable $\mathrm{PAR}_{0}$

b) variable MLD

c) variable $\mathrm{PAR}_{0} \& \mathrm{MLD}$

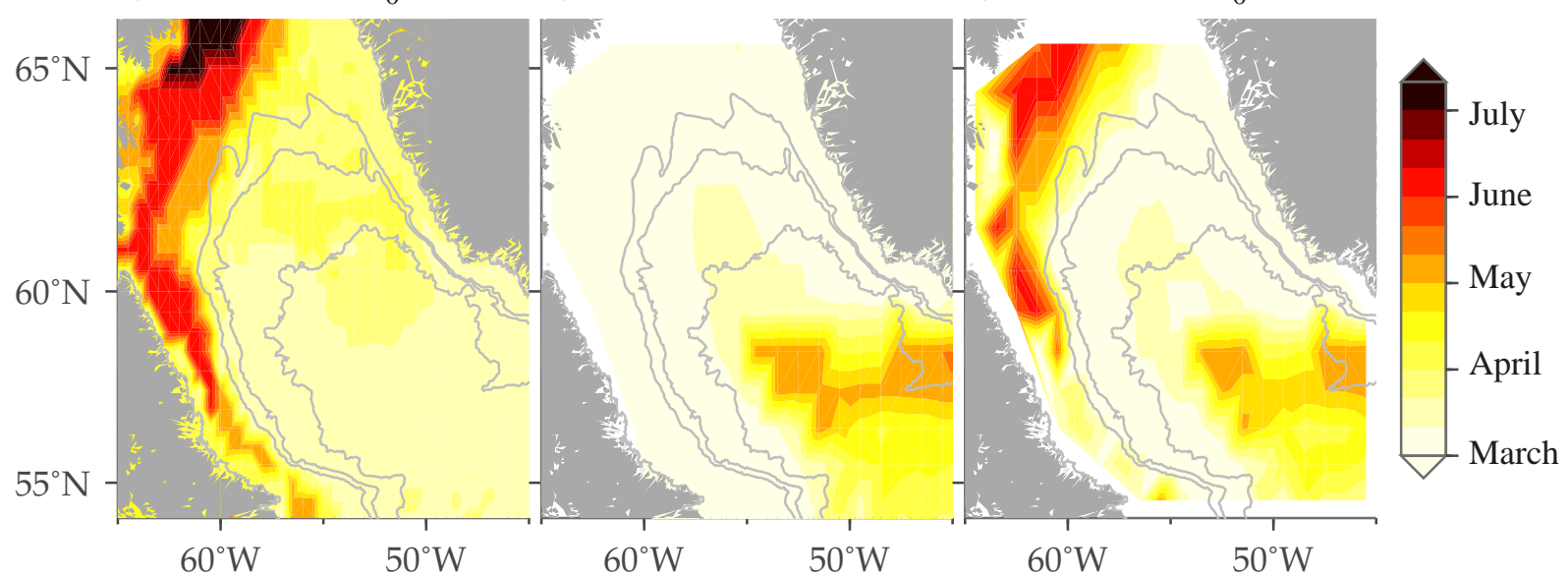

Figure 4: Predicted start days using Sverdrup's critical depth theory for three cases: (a) spatially variable light cycles $\left(\mathrm{PAR}_{0}\right)$, (b) spatially variable mixed layer depth cycles, and (c) variable light and mixed layer depth. In (a), note the Labrador shelf blooms later than the north and central Labrador Sea. In (b), the north Labrador Sea blooms before the central Labrador Sea.

a) Total anomaly

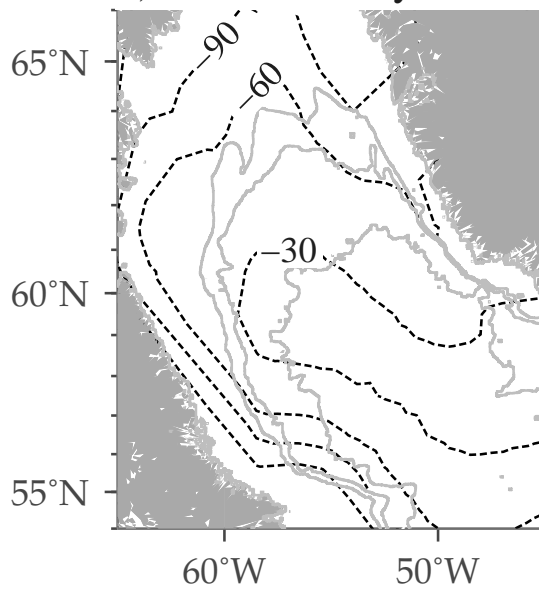

b) Haline anomaly

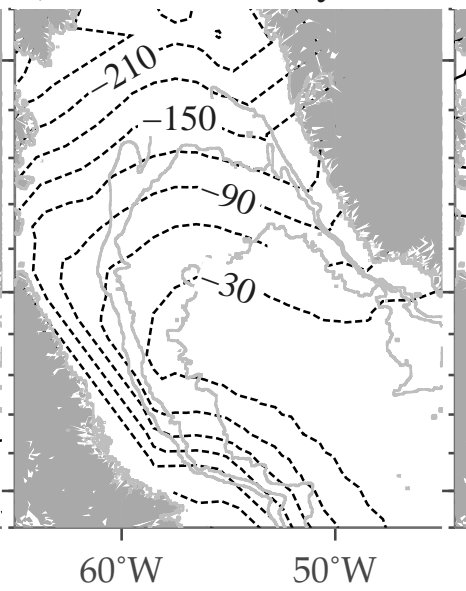

c) Thermal anomaly

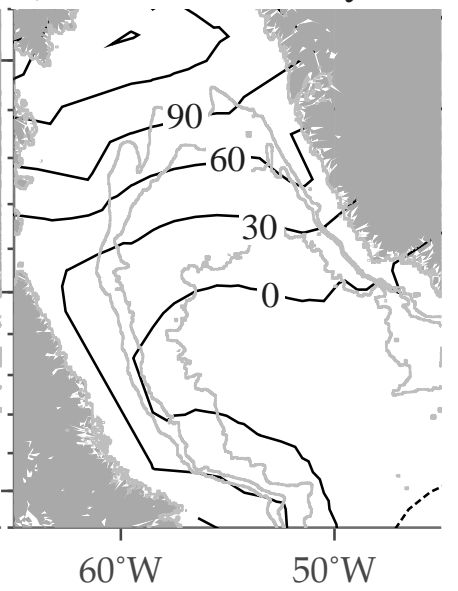

Figure 5: Buoyancy anomaly in May to $500 \mathrm{~m}$ from WOA 2005, shown as (a) total buoyancy anomaly, (b) anomaly due to temperature variations only, and (c) anomaly due to salinity variations only. Positive values are destabilizing (salty or cold) while negative values are stabilizing (fresh or warm). Stratification decreases towards the central Labrador Sea (towards positive buoyancy anomalies) in spite of destabilizing temperatures (positive buoyancy anomaly) on the shelves. 
a)

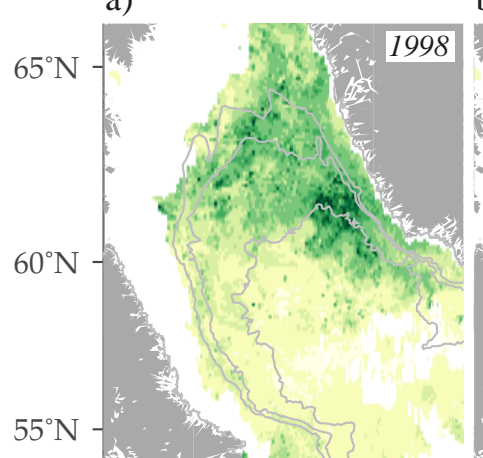

e)

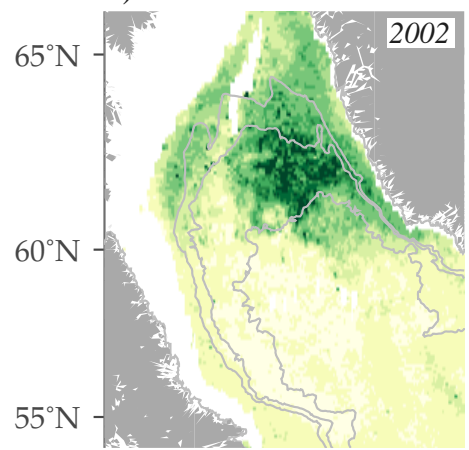

i) j)

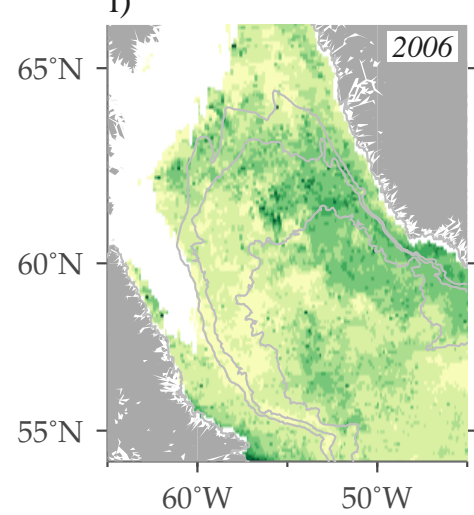

b)

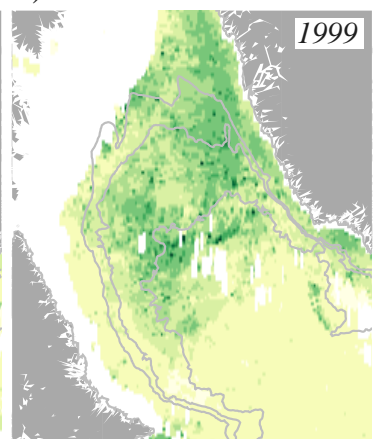

f)

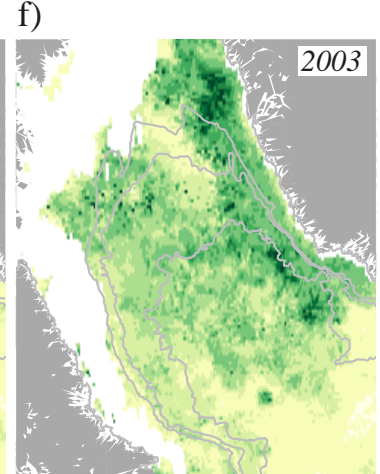

j)

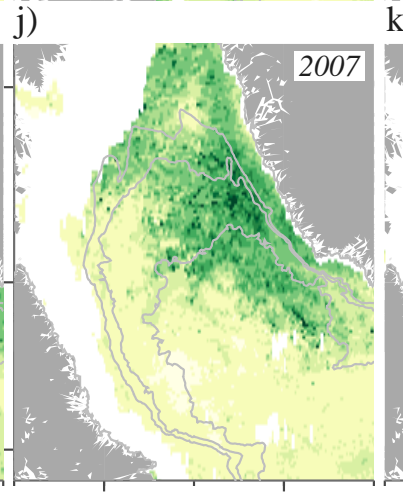

$60^{\circ} \mathrm{W}$ c)

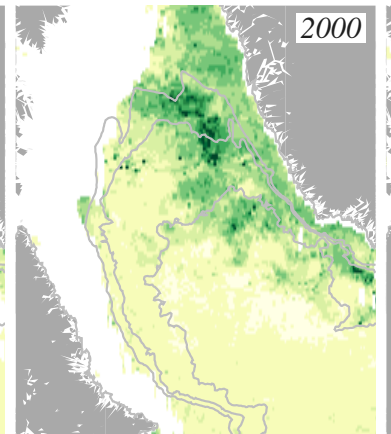

g)

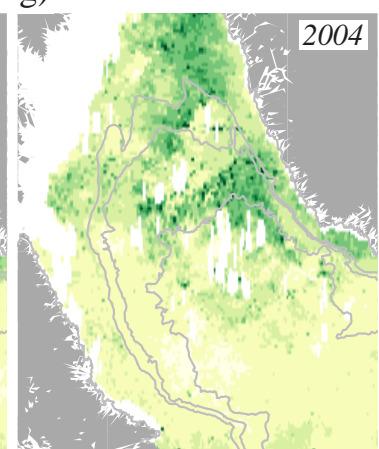

k)

d)

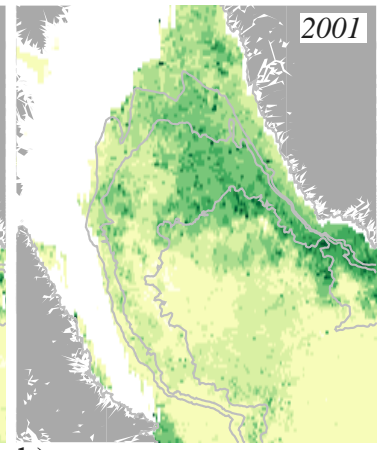

h)

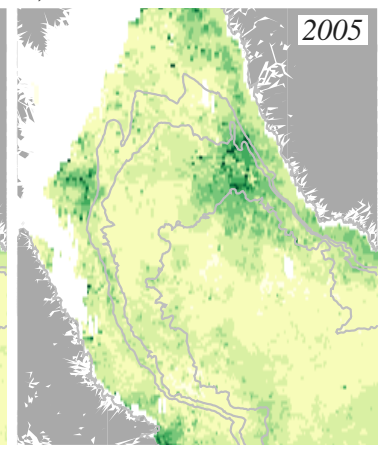

1)

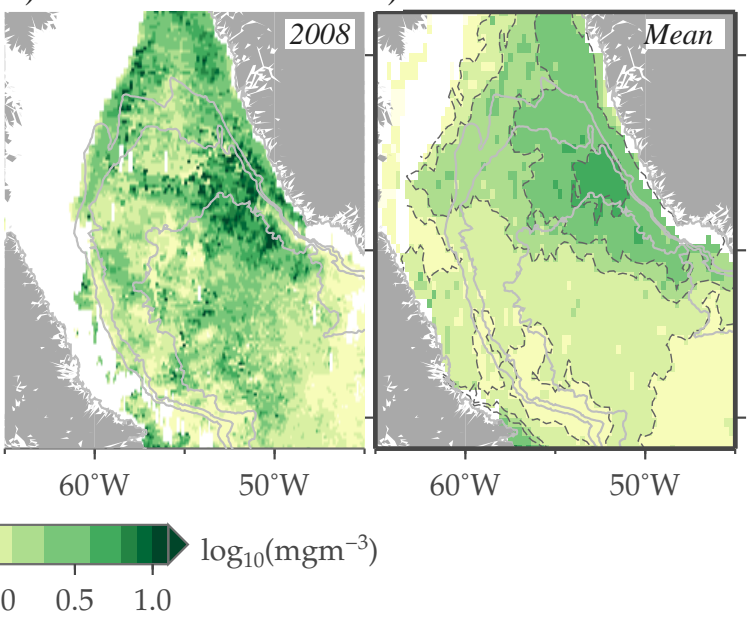

Figure 6: (a-k) Average of April and May daily chlorophyll images at $9 \mathrm{~km}$ resolution for each year, 1998-2008. (l) Average chlorophyll in April and May for all years, 1998-2008. 

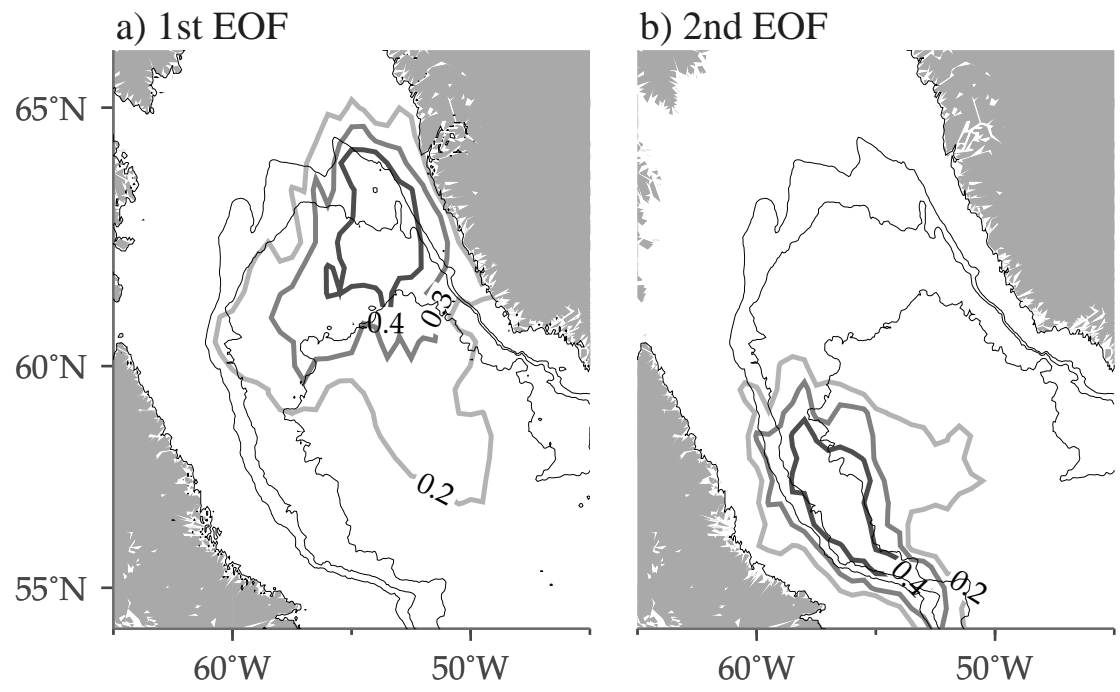

Figure 7: Biogeographic zones of the Labrador Sea determined using EOF analysis of SeaWiFS chlorophyll concentration from 1998-2008. The first two modes are shown as homogenous correlation maps, that is the correlation between the first and second principal component time series and the chlorophyll time series at each location. Only contours for which the correlation is significant $(p<0.05)$ are shown. (a) The first EOF explains $49 \%$ of the variability, with variability peaking off the west Greenland shelf north of $60^{\circ} \mathrm{N}$. (b) The second EOF contains $10 \%$ of the variability and is centered off the Labrador shelf.

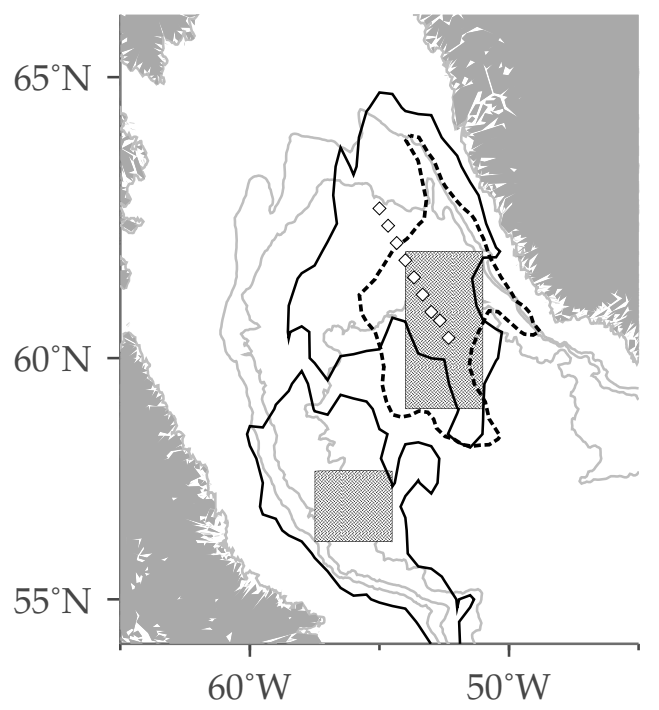

Figure 8: Map showing regions used to calculate annual indices. The two regions are in the shaded rectangles, the more northerly one corresponds to the north bloom while the south-westerly corresponds to the central Labrador Sea. The dotted outline is the region of high $\left(>50 \mathrm{~cm}^{2} \mathrm{~s}^{-2}\right)$ mean eddy-kinetic-energy. The two solid outlines correspond to a threshhold of 0.23 in the homogenous correlation maps. The diamonds are the locations where offshore geostrophic velocity anomalies were calculated, positive being perpendicular to this line, to the southwest. 


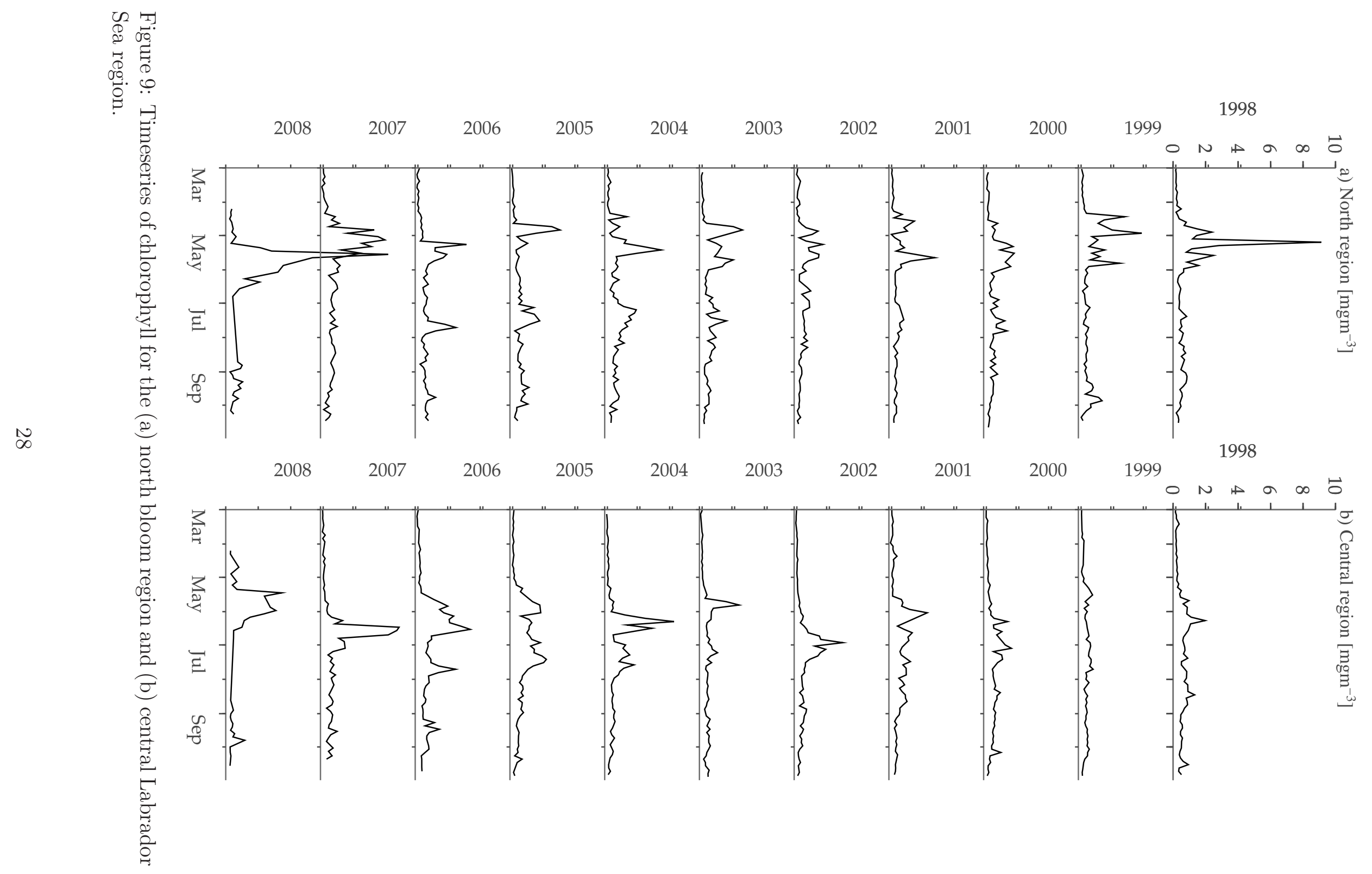




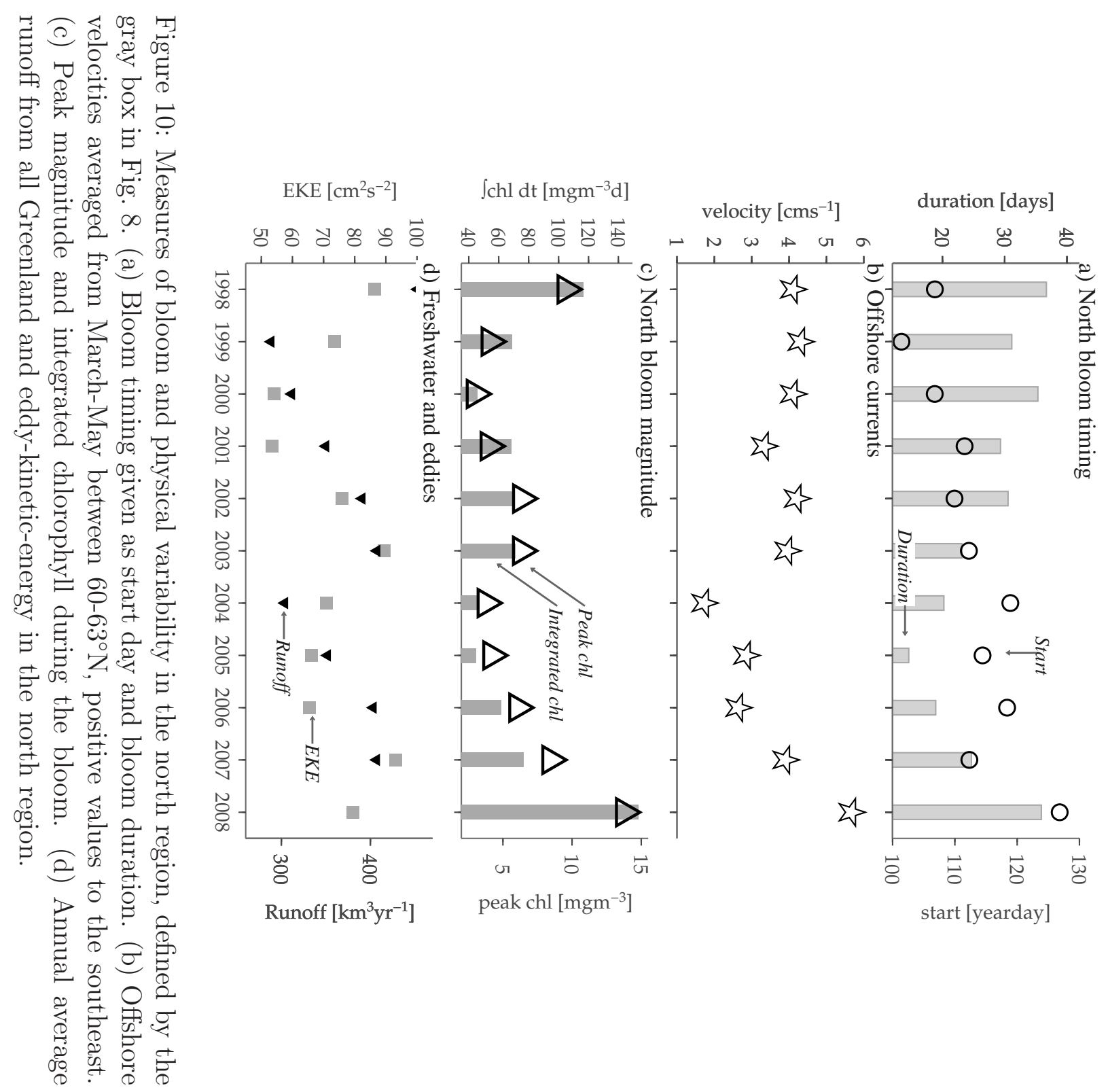



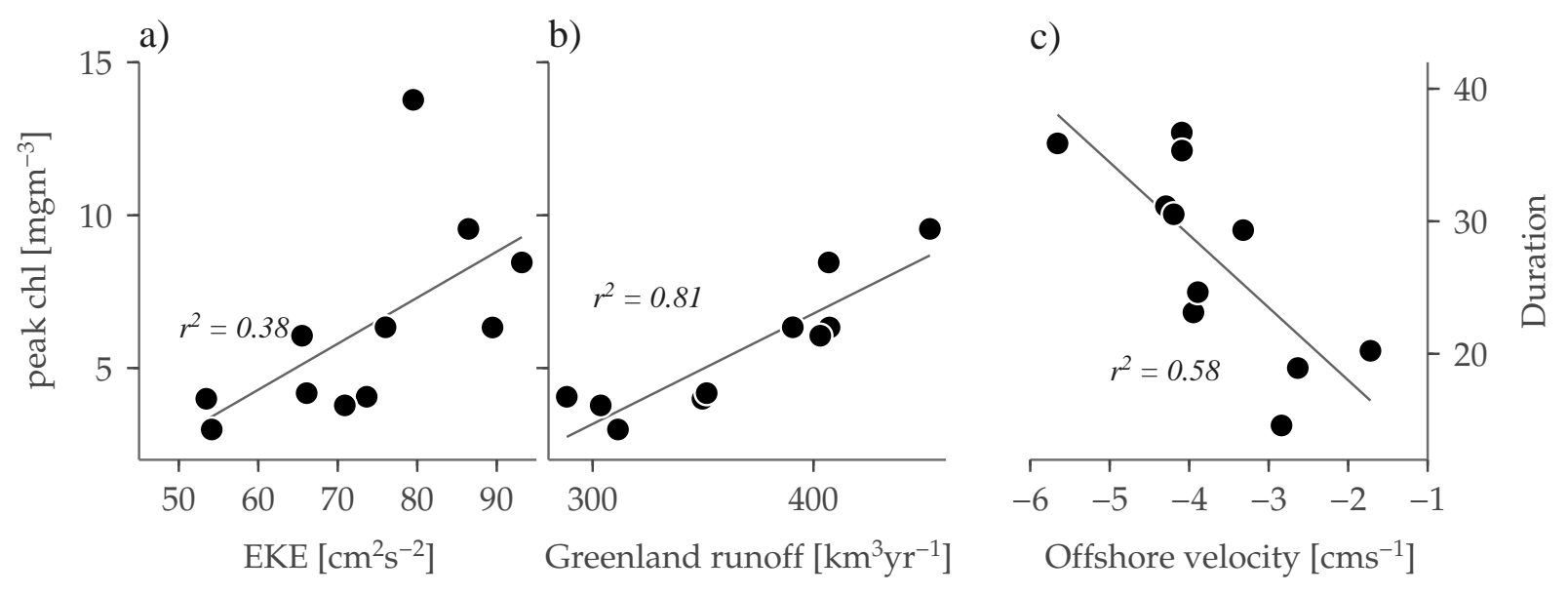

Figure 11: Linear regressions between biological and physical measures for the north Labrador Sea region. Scatter between annual peak bloom magnitude and (a) eddykinetic-energy and (b) runoff from Greenland and (c) between bloom duration and offshore velocity.

\begin{tabular}{l|ccc} 
(a) & peak & $\int d t$ & start day \\
\hline Irradiance (PAR) & 0.0 & 0.0 & $\mathbf{0 . 5}$
\end{tabular}

\begin{tabular}{l|ccc} 
(b) & peak & $\int d t$ & duration \\
\hline Greenland runoff & $\mathbf{0 . 8}$ & $\mathbf{0 . 5}$ & 0.0 \\
Irradiance (PAR) & $\mathbf{0 . 7}$ & $\mathbf{0 . 7}$ & 0.1 \\
Offshore-velocity (spring) & $\mathbf{0 . 4}$ & $\mathbf{0 . 5}$ & $\mathbf{0 . 6}$ \\
Eddy-kinetic-energy & $\mathbf{0 . 4}$ & 0.2 & 0.0
\end{tabular}

Table 1: Table of correlation coefficients between physical and biological indices for the (a) central and (b) north Labrador Sea regions. All physical indices were available for 19982008 except for Greenland runoff which was only available from 1998-2007. Significant correlations at $95 \%$ are boldface. 